\title{
Constructionist Theory of Representation in Language and Communication: A Philosophical Analysis
}

\author{
Bonachristus Umeogu' ${ }^{1}$, Ojiakor Ifeoma² \\ ${ }^{1}$ Department of Philosophy, Faculty of Arts, Nnamdi Azikiwe University, Awka, Nigeria \\ ${ }^{2}$ Department of Mass Communication, Faculty of Social Sciences, Nnamdi Azikiwe University, Awka, Nigeria \\ Email: ojiakor99@yahoo.com
}

Received February 25 ${ }^{\text {th }}$, 2012; revised March 27 ${ }^{\text {th }}$, 2012; accepted April $11^{\text {th }}, 2012$

\begin{abstract}
There is nothing as an innocent word because every word no matter how simple it sounds is loaded with meaning. For communication to have taken place, the meaning of a word or symbol is grasped and understood by the receiver. This paper maintains that there are variables which influence the construction and decoding of meaning with the resultant effect that no two individuals construct meanings in uniform way.
\end{abstract}

Keywords: Language; Representation; Communication; Meanings

\section{Introduction}

When you hear or see the word construction, what comes to mind? The picture is that of "carefully" building, putting up or arranging something to make a meaning or has a desired image. This tells me that construction is a personal thing, done by an individual to suit his desires, fantasies and needs at a particular point in time.

With regards to language and communication, what role does construction play? What is language? What does constructionist theory posits? Language and communication go hand in hand. In fact, suffice me to say that language is the vehicle of communication. You cannot communicate without language despite the form it takes. A sign, a gesture, a touch or a look, and even a smile are all forms of language used to communicate to another. Understanding the language hitherto need some form of decoding and that is where construction comes in. Using a photograph for instance, it cannot mean the same thing to everybody. If it is in a classroom, a picture has a different meaning to everyone depending on what they constitute it to mean. In other words, everyone sees things differently.

If you are in a communication situation for instance, being exposed to advertising images in the forms of pictures as the language of communication, how are you able to understand what the advertiser is trying to say? How is one able to say and conclude that this advert or image is what is obtainable in my society? How are readers able to question the "reality" of advertising images and other communication processes? This is what this paper sets out to unravel: how meaning is generated from something that looks simple like a photograph. At this point, signifying practices come into play. What is meant by signifying and its practices?

\section{Representation}

"Representation according to www.Wikipedia.com is the use of signs that stand in for and take the place of something else. Signs are arranged in order to form semantic constructions and express relations”. Representation also suggest a process whereby a pre-existing given, whether it be a physical object or philoso- phical abstraction, is translated so that it can be comprehended and experienced by a recipient, an observer, an audience (Geraghty, 2005).

However we choose to look at it, it involves something that has a resemblance to and can be used to stand in for something or someone. Therefore, what distinguishes human from other animals is their ability to create and manipulate signs. According to Wikipedia, "Aristotle deemed mimesis as natural to man, therefore considered representations necessary for peoples' living and being in the wild”.

Representation as listed by Aristotle in wikipedia has three forms namely:

1) The object: The symbol being. This looks at the "who" that is being represented. This might either be males or females or both.

2) Manner: The way the symbol is represented. This answer the "how" question in representation. To understand the manner of representation involves construction of meanings as portrayed by the "means" of representation.

3) Means: The material that is used to represent it. Here, the means of literary representation is language. For this paper, the language will be advertisements.

\section{Social Constructionist Theory of Representation}

For a clearer understanding of how this theory can be related to language and communication, there has to be an explanation of this theory so that all and sundry can relate it to their individual communication situations. What then does the social constructionist theory of representation posits? According to Hall (1997),

meaning is constructed by the individual users of language. Things do not mean; we construct meaning using representational signs. The translatability is not given by nature or fixed by the gods. It is the result of a set of social conventions.

It is fixed socially; fixed in culture. That is what social constructionist theory of representation is all about. The bottom line in this definition is that meaning does not inhere in things 
rather it is constructed, produced and understood in relation to oneself. When you do not understand a sign in whatever form it takes, it makes no meaning to you whatsoever, which means that communication cannot be said to have taken place. For instance, if you have not been to a driving school or familiar with traffic signs, traffic signs on the road will make little or no meaning to you because you would not know how to relate to them.

Another instance was given by Geraghty, (2005) who explained social constructionist theory of representation at play using a photograph. According to her,

the meaning of the photograph is not hidden or imamnent in the picture but is constructed through a range of signifying practices. During the process of recognition and understanding, we relate what we see to a wider set of understanding.

That is, if you see a picture of a bent arrow on a road, you will recognize and relate it to one of the traffic signs and will therefore understand it to mean that there is a bend ahead. This in turn will make you to apply the brakes to avoid skidding off the road. Here, the power of selective recall comes into the picture. This is because you were able to recall where and what that sign means and to give your feedback to the communication message by applying speed control. Is the above example an instance of a communication process? Well, to answer the question, we have to define communication and the communication process.

There are many definitions of communication as there are writers. That notwithstanding, let us look at one definition since the writers all say the same thing in different ways. Shrimp (2000) defines "communication as the process whereby thoughts are conveyed and meaning is shared between individuals or between organizations and individuals". He went on to throw more light on the word by writing that the word communication is derived from the Latin word communis, which means "common". Communication can then be thought of as the process of establishing a commonness, or oneness, of thought between a sender and a receiver. The key point in this definition according to Shimp is that there must be a commonness of thought developed between sender and receiver if communication is to occur.

This is because communication is something we do with another person, and not something we do to another person. It is more or less like a give and takes situation where there is an active sender and receiver. This means that it is not a solo thing but there must be somebody or people at the receiving end to decode whatever is coming out from the communicator. This will be clearer with the communication model of source- message-receiver-feedback.

Source is the originator of the message and is willing to share with others. Message is the content of the expression of one's thoughts, ideas, beliefs and opinion. Channels are the paths or media through which the message moves from the source to the receivers. It can be said to be how the message gets to the target audience. The receiver or the decoder is the recipient of the message. Here, he/she tries to interpret or deduce meanings from the message. Noise is anything that interrupts the communication process. It does not have to be a loud noise to be considered noise in communication. Noise can take any of the following forms; use of big words unknown to the audience; a static TV channel; a blurred picture on a newspaper or maga- zine page etc, (Okunna, 1999). Whichever way you look at communication, it embodies sharing or transmitting a desired message to have an intentional or desired influence.

Now to answer the question whether decoding a sign is communication, my answer is yes and this is the reason. Here, the source of the message is the public safety department; the message is that there is a bend ahead; the channel is in the form of a sign which is the arrow; the receiver is that driver plying the road at the moment; and the feedback is in the driver breaking the speed limit so as to navigate the bend safely. Noise will be introduced if the sign is faint or not big enough so as not to catch the attention of the driver or if the driver is not familiar with traffic signs.

Explaining further on signs as a language in representation, Hall (2000) explains that:

cultural meanings are not in the "head". It is produced by the practice for representation whereby the meaning depend not on the sign, but on its symbolic function.

He went further to state that it is because a particular sound or word stands for, symbolizes or represents a concept that it can function as a language for a particular culture. For instance, writing a sign in Chinese or Swahili will not function as a language to Nigerians because they do not understand the sign in order to understand what meaning it is supposed to convey. While waving at someone is a way of calling them forward, others see it as a permission sign to leave or go back. If you are a Nigerian being waved at, you will understand it to mean you are being greeted or wanted to come closer. In another culture, a receiver of a wave will interpret it to mean "discharge". What I am trying to explain in essence is that culture plays an active role in constructing meanings.

Be that as it may, I see social constructionist theory as a theory with a human face; a theory that understands the uniqueness of human beings and accords man the respect of a higher animal capable of deconstructing forms of communication to achieve meaning. The uniqueness comes in as a result of the fact reiterated in the introductory part that no word or sign is innocent; and everyone sees things differently. Yes! It has a human face because you can relate it to every social activity. Man has been said to be a social being which means that consciously or unconsciously, he communicates with his environment. Despite the communication situation be it formal or informal, some form of message decoding is involved for effecttive message understanding.

\section{Advertisements as a Form of Language and Communication}

The use of pictures or images in advertising has led to a situation where images of males, females or both are used to represent the concept of a product or services. However, on several occasion as a fleeting glance at some advertisements whether on print, outdoors or electronically reveals, there seems to be an arbitrary use of the images whereby there is no defined relationship between the product and the model. Pierce sees it as the relationship between the sign, the signifier and the signified.

Using advertisement as a language, how does it communicate to us and with what resultant effect? Well, it does communicate with us because "the construction of masculinity and femininity is through the placement of roles of the males and females in 
advertisements (O’Barr, 2006). Social practices which include advertising take place within representation and are saturated with meanings and values which contributes to our sense of who we are-our culturally constructed identities". (Gledhill, 1997 in Ojiakor, 2010).

\section{Ways of Reading Advertisements}

Katherine Frith (1998) in Lukas (2002) discusses three approaches to reading ads. Firstly, there is the surface meaning which consists of the overall impression that a reader might get from quickly going through an advert or picture. For instance, if you get a picture, the surface meaning is the first image that you will have of the picture; appreciating the aesthetic value of the picture without necessarily being concerned with the message. According to Frith (1998), "You can describe the surface meaning by simply listing all the people and objects in the advertisements". Secondly, there is the advertisers' intended meaning which is the meaning that the advertisers are paying huge amounts of money for the advertisers to take home with them. It is the "sales message that the advertiser is trying to get across or the preferred or expected meaning that a reader might get from an advertisement". An example of the advertisers intended meaning is like the caption of peak milk that reads "it's in you". Here the message is that if you want to exploit your hidden potentials, all you need is to drink peak milk. Finally there is cultural/ideological meaning which relies on the background of the reader. Here, we all make sense of ads by relating them to our culture and the shared belief systems held in common by most people. In all, construction of any message or meaning is directly or indirectly influenced by sex, cultural orientation and level of exposure. In fact, this is where the constructionist theory comes into play and the factors of sex, cultural orientation and level of exposure now acts as intervening variables that ensure that there is little or no room for uniform reading.

\section{Factors That Affect Construction}

Sex: The biology of an individual to a large extent determines their perception which in turn affects their construction of meaning. In a society like ours where men are thriving on their patriarchal dividend, their ways of seeing and reading advertisements are quite different from a woman's view. Situations where a woman will criticize the immodest dressing of a female model, the man will not; rather he might focus on the aesthetic value of the overall picture.

The problem with this factor is that the term man or woman is faulty in that being a man or woman is experienced differently. A woman who is an illiterate or a housewife will have different experience at being a woman as experienced by a working class lady. "Being a man or woman" is experienced differently according to one's age, class, ethnicity, sexual orientation and what have you. The way our fore parents experienced living is radically different from what is obtained in this present dispensation. This however leads to the next factor which is cultural orientation.

Cultural orientation: Nothing is constant except change which means that even the so called way of life of the people (culture) is subject to change. I believe that culture is a closely guarded jewel yet is directly or indirectly made to change. Look around you and you will notice the change in our culture. In Nigeria for instance, the dressing, housing and even eating habits have changed overtime; orientation updated to fit the twenty-first century. There was a time when women were seen and not heard. Well, gone are those days because women are now trying to make their voices heard over those of men. Explaining that culture plays a role in construction of meaning, Hall (1997) opines that:

The translatability is not given by the gods. Rather, it is fixed socially, fixed in culture". This shows that what is obtainable in a particular society in form of culture, influence the meaning given to things.

Another researcher also has this to add:

Objects and people do not have a constant meaning, but their meanings are fashioned by humans in the context of their culture, as they have the ability to make things mean or signify something (www.wikipedia.org/wiki/representtation).

Saussure concurs by opining that "the representation of a signifier depends upon a person's cultural, linguistics and social background. In explaining this, the word 'sister' in Australia may mean blood relation while an Aboriginal Australian may associate the term 'sister' to represent a close friend that they have a bond with" (www.wikipedia.org/wiki/representation)

The point I am trying to make is that culture of the people at any point in time affects the meanings that is given to life and its issues.

Level of Exposure: "Semiotics is an analytical tool which helps to understand how signs and symbols are manipulated to form structures of meaning”, Williamson (1990). In the same vein, Adum (2006) has this to say;

Semiotics helps us to understand how advertisements manipulate powerful symbols to persuade the receiver, viewer or listener.

What has all these got to do with level of exposure? How well one is versed in the knowledge of semiotics determines how efficient one is in constructing or deconstructing pictures in advertisements. A person who was taught semiotics analysis cannot be expected to literally read the picture same as an illiterate or even a literate who was not exposed to semiotics and its antics. Well, I had the opportunity of taking semiotics class and the way I see and understand meanings will not be uniform. I go beyond the aesthetic to the hidden meaning while another will look at the models dressing and their placements in the picture.

\section{Application of Social Constructionist Theory of Representation in Reading Advertisements}

Can there be any mention of the word representation without its channel, language. Language is one of the "media" through which thoughts, ideas and feelings are represented in a culture (Hall, 1997).

Advertising is a very powerful form of communication in modern society because it offers the most concentrated and sustained set of Images in our media system. Using an advert for Dior, a writer at

www.esfmemdia.com/page/advertisingrepresentation listed some questions that in attempting to answer them, one is actively involved in applying this theory to representation.

- "What is the dominant colour in the palette? What are the 
connotations of this colour?

- What is at the top of the visual hierarchy? The woman or the perfume? Is this what you would expect?

- Which of the woman's physical features have been emphasized? Why? How?

- Who is this advert supposed to appeal to? Women, men or both? Could this type of representation have any harm? Can adverts establish unrealistic expectations in the audience”? www.esfmemdia.com/page/adverstising representation

Attempting to answer these questions will form our application of the theory in reading advertisements or pictures. Firstly, let me describe the pictures that were used for this application:

Picture Mimee: Mimee noodles advert had the picture of a lady with her braids scattered like the noodles, her eyes were closed as if lost in ecstasy. Below her image was a picture of noodles on a plate and the bold caption "have mee".

Picture Jadore: A fragrance ad for Christian Dior has a slim and gorgeous woman in a strapless dress looking at the camera with a bottle of the perfume in front of her. The image, the product and the background was golden yellow, and the design on her body was the same on the bottle.

Picture Honeywell: The advert for a baking flour called Honeywell flour. The image was a male chef holding a wad of notes with a big smile on his face. Beside him were loaves of bread and a bag of the flour.

Picture Grand: The advert was for a hotel called "Grand hotel". It have snapshot of various parts of the hotel alongside the picture of a light skinned female in a black bikini with her hair let down.

Picture Tura: Tura soap has the image of a slim and light skinned woman putting on a short black gown and crossed her legs leaving so little for imagination. She was also looking at the camera. In the bottom left side of the space were also passport sized pictures of other women.

Picture Citico: A dark well muscled bare chested man with a black tyre imprint on his arms was used as the image for this plastic chair advert.

\section{Question:}

- What is at the top of the visual hierarchy? The woman or the perfume? Is this what you would expect?

Answer:

In all the sampled pictures with exception of pictures Grand, Citico and Honeywell that evenly shared the advertising space, others had images that were more dominant than the advertised products. Dominance here means that the images are larger and thereby took up almost all the space that one may not be wrong to assume that the models are the advertised products. If you mentally look closely at picture Mimee for an example coupled with the caption that read "have mee", you may erroneously conclude that it is the exotic looking lady that is specially meant to be 'had' at that point in time. In addition, she had her eyes closed as a prey waiting to be eaten by a predator.

In picture Hi-malt, there was not even a tiny picture of the bottled drink. Rather, what we saw was the face of the lady imprinted on a supposed bottle shape so that what we see as the drink is the face of a woman meant to give "high satisfaction" (advertising message). In this case, there is no room for dominance struggle to arise since the models image was the only one on the advertising space.

\section{Question:}

- What is the dominant colour in the palette? What are the connotations of this colour?
Answer:

This paper will answer using the Jadore fragrance by Christian Dior. The reason why Nigerian adverts are excluded in this category is that, Nigerians from a look at the billboard advertisements have not yet mastered the art of using coloring and lighting to create meaning.

You must have heard of terms like soft colors, warm colors, harsh color and what have you. The color of the image, the product and the background was a perfect blend of golden and yellow rolled into one such that there is no telling them apart. The color "golden" like the rays of the fading sun in Africa is always seen as soft, alluring, inviting and pleasing to the eyes. Looking at that advert is like watching the sun set and having that warm and rare feeling that comes with appreciating the beauty of nature at first hand.

This paper do not want to say that the coloring is suggestive at the risk of looking as an anti feminist, but connotatively, will say that the color suggest sexiness or allure which the product is all about. Well the underlying message is that the use of that fragrance will make you feel "sexy" and pleasing to the eyes. Whose eyes? Is that what perfume or fragrances really does?

\section{Question:}

- Which of the woman's physical features has been emphasized? Why? How?

Answer:

The researchers do not want to focus on female since the sample also had male images. For pictures Tura, Mimee, Grand and Jadore that had female images, the features highlighted were the fine legs, smooth bodies and charming faces respectively. In particular, pictures Hi-malt and Mimee had the focus on their faces. Why? Well, maybe for the erotic and giddy feeling to be heightened by a close up shot. Also, to portray how lost the models are in the world of the products. That look and that feeling cannot be deduced from a distance.

In Tura and Grand pictures, the emphasis was on their smooth, velvety looking skin. If a girl is wearing a bikini or mini gown, what else than to look at the body which is open to be surveyed? Another answer to the why can be seen in the words of Dyler (1982) who wrote

that advertisers use images of beautiful women as men and women like looking at beautiful women. While the men admire them, women admire what makes the men admire them.

Beauty images of women in the media are unattainable for all but a very small number of women. The logic is that women who are insecure about their bodies are more likely to buy beauty products because of the model www.beauty\&body image in the media). "Images of female bodies are everywhere. Women and their body parts sell everything from food to cars”. www.beauty\&body image in the media). This can explain why those features were highlighted to get the viewer hooked. At this point, the question is if sex and the highlights of body parts appeal.

Arens (2006:390) writes that "sex appeal is one of the uses of sex in advertising in recent times". An example he used to back his claim was an advert for auto parts that had the image of a young lady holding a grease gun cartridge in each hand and leaning over to exhibit an ample amount of cleavage. What about the message on the advert? It read "this is Debbie; she wants you to have this pair in your car". Which pair are we 
supposed to have; the tools in her hands or the pair on her chest?

On the other hand where we have the pictures that had males as their images, it was only the picture Citico that emphasized the man's firm, well muscled body. There was no sexual connotation as can be found in the women's corner, but rather by association, one can relate the strength and build of the man to those of the plastic chairs.

\section{Question:}

- Could this type of representation have any harmful effects? Can adverts establish unrealistic expectations in the audience?

\section{Answer:}

Representation leads to stereotypes that often lead to misrepresentation and misconstruction. Advertising images teach how and what men and women should be. It also teaches us how to see and respond to each other. If the present society feels that it is not harmful or does not have any harmful effects, what happens to the next generation? Representation always locates women in the kitchen, what about those women who hate to cook? There are men who love to cook but to the society, that is "unnatural".

In some homes, there are problems because the man expects the woman to perform her womanly duties-cooking and taking care of the home. The woman on the other hand sees men as half men if they do not live up to the image of being successful at their chosen careers. In fact, many women have questioned manliness if the man fail to adequately provide for the family (men also question women).

Presently, one of the harmful effects of unrealistic expectations is that of pressure under which men and women are cracking; marriages are folding and dreams are being shattered. Goffman (1979 in Ojiakor, 2010)

"advertisers do not create the images they depict out of nothing. They draw upon the same corpus of display that we all use to make sense of social life". If the society constructs women as an object of vision, advertisers tap into that. If men are seen as all powerful, embodiments of strength and success, advertisers clinch it and portray same images to reflect in their advertising themes.

Well, we all are directly or indirectly feeling the brunt. If this is the way we imagine things to be, then we are pressured into the state of "oughtness" to fit the current theme.

\section{Question:}

- Who is this advert supposed to appeal to? Women, men or both?

\section{Answer:}

In all the sampled adverts, it is meant to appeal to both men and women alike. Contrary to popular belief, there are many men who use creams and soaps on a daily basis; there are men who are chefs and actually make a living from cooking. Again, even if the product is for females, it might appeal to a man who would like his partner, mother or sister to have the same look or get the benefits derived from using a particular product.

Most times, models appeal to the audience outside the context of the advertised products. For example, the advert might be for a fragrance but the mere use of Hugh Jackman (an actor) or Batista and Randy Orthon (wrestlers) is enough to push a man into working out to have abs like theirs.

The point we are trying to make is that all adverts appeal to every human being sex notwithstanding. The only difference might be in the degree of the appeal.

\section{Conclusion}

It has been agreed that it is through representation that man comes close to reality. Also, there can be no room for representtation without language. Language is the means of representation; one apprehends reality only through representation of reality, through texts, images etc.

This paper has tried to show how constructionist theory of representation is actively involved in making meanings out of different language forms in our different societies.

Since everyone sees things differently coupled with the nature of semiotics, there can never be a uniform reading in advertisement as previous research have shown. However, what we see in advertisement and other forms of communication all reflects the cultural life of any society at that point in time. On this note, this paper reiterate that man despites age and orientation is actively involved in making meaning out of signs that confront man on a daily basis. Objects and people do not have a constant meaning, but their meanings are fashioned by humans in the context of their culture, as they have the ability to make things mean or signify something.

Also, when we fail to understand the language or sign, the communication process of source-message-channel-receiver has been disrupted and effective communication cannot be said to have taken place.

\section{REFERENCES}

Adum, A. (2006). Believability of Advertising Message: An Evaluation of Audience Perception in Nigeria. M.Sc Thesis, Awka: Nnamdi Azikiwe University.

Advertising Representation (2012). URL (last checked 23 January 2012). www.esfmemdia.com/page/adverstisngrepresentataion

Arens, W. (2006). Contemporary Advertising. New York: McGrawHill.

Frith, K. (2005). Undressing the Ads: Reading Culture in Advertising. www.genderads.com

Geraghty, C. (2005). Representation, Reality and the popular culture: Semiotics and the Construction of Meaning. In J. Curran, \& M. Gurevitch (Eds.), Mass Media and Society (pp. 46-59). Malta: Gutenberg Press.

Gillian, D. (1982). Advertising as Communication. London: Routledge Press Inc.

Gledhill, C. (1997). Genre and Gender: The Case of Soap Opera. In S. Hall (Ed.), Representation: Cultural Representations and Signifying Practices (pp. 337-386). London: Sage Publication.

Griffiths, T. (2010). Media Representational Theory. URL (last checked 23 January 2012). www.slideshare.net

Hall, S. (1997). Representation: Cultural Representations and Signifying Practices. London: Sage Publication. 337-386.

O’Barr, W. (2006). Representation of Masculinity and Femininity in Advertising. Advertising and Society Review, 7.

Ojiakor, I. (2010). A Study of Gender Representation in Billboard Advertisements. M.Sc Thesis, Awka: NAU.

Pickering, M. (2001). Stereotyping. Palmgrave.

Representation (2012). URL (last checked 23 January 2012). www.wikipedia.org/wiki/representation

Scott, L. (2005). Gender ads project. In T. Shimp (2002), Advertising promotion. San Diego, CA: Harcourt Publishers.

Social Constructionism (2012). URL (last checked 23 January 2012). www.wikipedia.org/wiki/social construction

Vulkerich, M. (2002). URL (last checked 23 January 2012). www.ucmt.uchicago.edu/glossary 


\section{B. UMEOGU, O. IFEOMA}

Williamson, J. (1990). Decoding Advertisements: Ideology \& Meaning in Advertising. London: Marian Boyars. www.beauty\&bodyimageinthemedia www.womenissues.about.com 